\title{
The effect of estradiol on granulosa cell responses to FSH in women with polycystic ovary syndrome
}

\author{
Michael V. Homer ${ }^{1}$, Marcus A. Rosencrantz ${ }^{2}$, Rana F. Shayya ${ }^{3}$ and R. Jeffrey Chang ${ }^{1,4^{*}}$
}

\begin{abstract}
Background: The influence of estradiol $\left(E_{2}\right)$ on granulosa cell (GC) function has not been tested clinically in women with polycystic ovary syndrome (PCOS). The objective of this study is to determine if $E_{2}$ influences $G C$ responses to FSH in women with PCOS.

Methods: This is a two phase, single cohort study conducted over a 2-year period at a single academic center. Nine women with PCOS according to NIH criteria. In Phase 1, FSH stimulation of GC responses as measured by $E_{2}$ and Inhibin B (Inh B) were assessed before and at 5 and 6 weeks after GnRH agonist administration. In Phase 2, the same protocol was employed with the addition of an aromatase inhibitor (letrozole, LET) administered daily beginning at week 4 for 2 weeks.

Results: In Phase 1, recovery of FSH, $E_{2}$ and Inh B from ovarian suppression occurred at 5 and 6 weeks after GnRH agonist injection and preceded resumption of $\mathrm{LH}$ and androgen secretion. In Phase 2, hormone recovery after GnRH agonist was characterized by elevated FSH and suppressed $E_{2}$ levels whereas recovery of LH and androgen levels were unchanged. In Phase 1, FSH stimulated $E_{2}$ and Inh $B$ responses were unaltered during recovery from ovarian suppression. In Phase $2, E_{2}$ and Inh B fold changes after FSH were significantly reduced at weeks $5(p<0.04)$ and $6(p<0.01)$, respectively.
\end{abstract}

Conclusion: In anovulatory women with PCOS, chronic, unopposed $E_{2}$ secretion may contribute, at least in part, to enhanced ovarian responsiveness to FSH.

Trial registration: NCT02389088

Keywords: Polycystic ovary syndrome, Granulosa cell, Estradiol, FSH, Inhibin B

\section{Background}

The characteristic features of polycystic ovary syndrome (PCOS) are anovulation, androgen excess, and polycystic ovary morphology. Anovulation is associated with modest estradiol $\left(E_{2}\right)$ secretion derived primarily from peripheral extraglandular conversion and minimal progesterone production. However, in vitro and in vivo studies have demonstrated that granulosa cells (GCs) from women with PCOS are hyperresponsive to FSH stimulation compared to responses observed in normal GCs. These findings

\footnotetext{
* Correspondence: rjchang@ucsd.edu

${ }^{1}$ Reproductive Medicine, University of California, 200 West Arbor Drive MC: 8710, San Diego, CA 92103, USA

${ }^{4} 9500$ Gilman Drive \#0633 La Jolla, San Diego, CA 92093, USA

Full list of author information is available at the end of the article
}

suggest that the ovary may contribute to circulating $E_{2}$ in women with this disorder [1-3].

Local production of $E_{2}$ may account, at least in part, for the enhanced CG response to FSH in PCOS. There is considerable evidence that estrogen enhances follicle function including responses to FSH. Diethylstilbestrol treated GCs from immature hypophysectomized rats produced greater $E_{2}$ release in response to $\mathrm{FSH}$ compared to that of untreated cells [4]. In addition, estrogen has been shown to influence GC cytodifferentiation by modulating follicular intracellular gap junctions, estrogen receptor content, and adenylate cyclase activity [5-7]. Synergy between $\mathrm{E}_{2}$ and FSH has been demonstrated in GCs with regards to increased FSH receptor binding and increased aromatase activity [8-10]. Corresponding 
in vivo efforts to demonstrate an effect of estrogens on $\mathrm{GC} \mathrm{E}_{2}$ production in women has been understandably difficult and not undertaken.

Previously, we and others have shown that in women with PCOS serum $E_{2}$ and inhibin B (Inh B) exhibit similar temporal responsiveness to $\mathrm{FSH}[11,12]$. These findings suggest that Inh B may serve as a marker of granulosa cell activity alongside $E_{2}$. In an effort to determine whether estrogen influences GC function in women with PCOS, we examined Inh B responses to FSH in the presence or absence of an aromatase inhibitor.

\section{Methods}

\section{Participants}

Nine women with PCOS were recruited for study. All subjects were between 18 and 35 years of age and exhibited clinical and laboratory evidence of hyperandrogenism, were either oligomenorrheic or amenorrheic and had greater than 12 antral follicles per ovary on transvaginal ultrasound that are consistent with criteria established by the NIH, Rotterdam, and Androgen Excess-PCOS Society. Mean age $( \pm \mathrm{SE})$ was $26 \pm 1.2$ years and BMI $( \pm \mathrm{SE})$ was $33.7 \pm 2.4 \mathrm{~kg} / \mathrm{m}^{2}$. Serum levels of 17-hydroxyprogesterone (17-OHP), TSH, and prolactin were within normal range. All patients were free of medication containing hormones for 3 months or greater prior to study.

The study was approved by the Human Research Protection Program at the University of California, San Diego (UCSD, IRB\#100023) and written informed consent was obtained from each participant before study.

\section{Procedures}

The study was divided into two phases. For Phase I of the study, participants were admitted on a random day to the Clinical and Translational Research Institute (CTRI) at UC San Diego for testing. Patients all had serum progesterone levels $<1.5 \mathrm{ng} / \mathrm{ml}$ and negative hCG tests. After placement of an intravenous line, each subject received an intravenous injection of recombinant human FSH (r-hFSH), 150 IU. Blood samples were obtained prior to and $24 \mathrm{~h}$ afterwards. After the last blood sample was obtained, each was given long-acting $\mathrm{GnRH}$ agonist (Depot Lupron), $3.75 \mathrm{mg}$ intramuscularly, to maximally suppress ovarian steroid production for one month after which serum $E_{2}$ levels gradually resume [13]. Ovarian suppression was employed to allow for FSH stimulation studies to be conducted during the recovery phase when the ovary and GCs regain responsiveness, thereby establishing uniform and comparable $\mathrm{E}_{2}$ levels in both phases of study. During this interval, FSH stimulation was repeated at the end of week 5 and week 6 .

For Phase II of the study, the same 9 participants were allowed to have a hormone-free washout period of
3 months from administration of $\mathrm{GnRH}$ agonist and 2 months from the prior dose of FSH. They were then re-admitted to the CTRI at UC San Diego for study. Similar to Phase I, they underwent a baseline FSH stimulation test after which $3.75 \mathrm{mg}$ of Depot Lupron was administered. At the beginning of week 4, each subject received an aromatase inhibitor, Letrozole (LET), $5 \mathrm{mg}$ daily, for 2 weeks to restrict increases of serum $\mathrm{E}_{2}$ levels that were observed in Phase I. The FSH stimulation test was then repeated at the end of week 5 and week 6 .

\section{Assays}

Serum concentrations of LH and FSH were measured by radio-immunoassay (RIA) with intra- and inter-assay coefficients of variation $(\mathrm{CV})$ of 5.4 and $8.0 \%$, respectively, for $\mathrm{LH}$ and 3.0 and 4.6\%, respectively, for FSH (Diagnostic Products Corp., Los Angeles, CA, USA). Serum concentrations of Inh B were measured by ELISA with inter- and intra-assay CV of 6.7 and 4.6\% (Diagnostic Systems Laboratories, Inc., Webster, TX, USA). The highly specific two-site ELISA Kit allows for quantitative measurement of dimeric Inh B in human serum. Assay sensitivity for Inh B was $7.0 \mathrm{pg} / \mathrm{ml}$. Serum concentrations of $E_{2}$, androstenedione (A) and testosterone (T) were measured by well-established RIA with intra-assay $\mathrm{CV}$ less than 7\%. $\mathrm{P}_{4}, 17-\mathrm{OHP}$ and dehydroepiandrosterone sulfate (DHEAS) were measured by RIA with intra-assay CV less than 7\% (Diagnostic Systems Laboratories, Inc., Webster, TX, USA).

\section{Statistical analysis}

Q-Q plot and boxplot were used to check the normality of the data. One-sample t-test and one-sample Wilcoxon signed-rank test were applied as needed to test the differences of hormone measurements at both baseline and after FSH stimulation for Phase I compared to Phase II. We also tested for differences in the log fold change of $\mathrm{E}_{2}$, Inh B and insulin hormone before and after FSH. For all analysis, $\mathrm{p}$ values of $<0.05$ were considered statistically significant. Statistical analysis were performed using the $\mathrm{R}$ statistical computing software (version 2.6.2, http://www.r-project.org, 2009).

\section{Results}

Serum hormone levels before and after GnRH agonist ovarian suppression (phase I)

Baseline circulating hormone levels for women with PCOS are shown in Table 1. Mean circulating levels of $\mathrm{LH}, \mathrm{FSH}, \mathrm{A}, \mathrm{T}, \mathrm{E}_{2}$ and Inh B before and following pituitary gonadotropin desensitization and ovarian suppression are shown in Fig. 1. As expected, serum $E_{2}$ levels at the end of week 5 and week 6 after GnRH agonist approximated pretreatment levels that reflected recovery 
Table 1 Baseline circulating steroid hormone and gonadotropin levels in women with PCOS.

\begin{tabular}{ll}
\hline & PCOS $(n=9)$ \\
\hline LH (IU/L) & $9.01[5.95-12.87]$ \\
FSH (IU/L) & $4.98[4.36-5.48]$ \\
T $(n m o l / L)$ & $1.3[1.17-1.54]$ \\
A $(\mathrm{nmol} / \mathrm{L})$ & $4.84[4.55-6.52]$ \\
$17 \mathrm{OH}-\mathrm{P}(\mathrm{nmol} / \mathrm{L})$ & $46.36[34.85-49.39]$ \\
$\mathrm{E}_{2}(\mathrm{pmol} / \mathrm{L})$ & $179[158-204]$ \\
\hline
\end{tabular}

Data are expressed as Median [IQ Range]). To convert to gravimetric units, multiply by the following conversion factors: $\mathrm{T}$ [ng/dL], 28.82; A [ng/dL], 28.65; $17 \mathrm{OH}-\mathrm{P}$ [ng/dL], 3.30; $\mathrm{E}_{2}[\mathrm{pg} / \mathrm{mL}], 0.27$

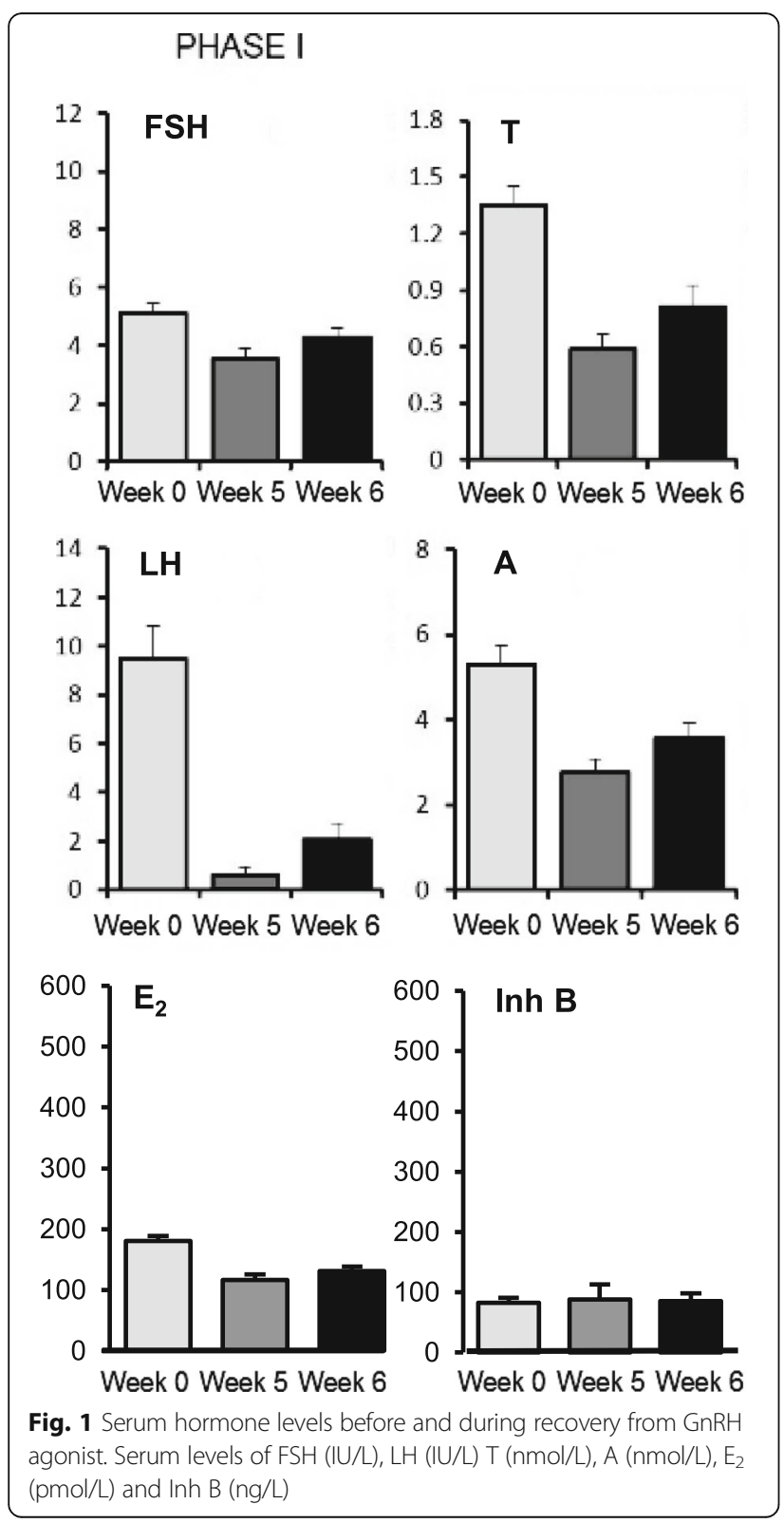

from ovarian suppression. Basal Inh B levels at the end of 5 and 6 weeks after GnRH agonist were not different compared to baseline serum values. Serum FSH levels at the end of week 5 were similar to baseline concentrations indicating complete recovery from pituitary desensitization. By comparison, $\mathrm{LH}$ and serum androgens at the end of week 5 remained lower than pre-GnRH agonist treatment levels. Subsequently, there were subtle increases of LH and androgen production by the end of week 6 .

\section{Serum hormone levels before and after GnRH agonist} ovarian suppression in the presence of LET (phase II)

In Phase II, corresponding levels of gonadotropins, $\mathrm{E}_{2}$, Inh $\mathrm{B}$ and androgens associated with the administration of LET during weeks 4 and 5 after GnRH agonist injection are shown in Fig. 2. Basal $E_{2}$ levels were significantly lower during daily LET administration (weeks 5 and 6) compared to corresponding values observed in Phase 1. Accordingly, these reduced $\mathrm{E}_{2}$ levels were associated with significantly higher basal serum FSH levels at week 5 and $6(p<0.01)$ as shown in Fig. 2. Notably, these increments of FSH were significantly greater than those observed without LET. In contrast to $E_{2}$, basal serum Inh B levels exhibited increases during LET treatment compared to the mean baseline value at week 0 , although these increments were not statistically significant. In Phase 2 patterns of increasing basal values of $\mathrm{LH}, \mathrm{A}$ and $\mathrm{T}$ levels during recovery were similar to those observed in Phase 1.

\section{$E_{2}$ and Inh $B$ responses to $F S H$ during recovery from} GnRH suppression in the absence and presence of LET In Phase I, the FSH-stimulated fold-changes of $E_{2}$ at 5 and 6 weeks during recovery were not significantly different from that observed at baseline, prior to GnRH agonist administration (Table 2). However, in Phase II studies with LET treatment, reduced basal $\mathrm{E}_{2}$ levels were accompanied by a corresponding decline of the foldchange $\mathrm{E}_{2}$ responses to $\mathrm{FSH}$ injection at weeks $5(p<0.04)$ and $6(p<0.01)$ compared to baseline. Similarly, Inh B responses to FSH in were not different in Phase I, but significantly decreased fold-changes following FSH were observed at $5(p<0.04)$ and $6(p<0.01)$ weeks.

\section{Discussion}

The results of this study are consistent with a facilitative role for $E_{2}$ on GC function in women with PCOS. This is suggested by the reduced fold-change responses of Inh $\mathrm{B}$ as well as $\mathrm{E}_{2}$ following FSH administration in the presence of lowered serum $\mathrm{E}_{2}$ levels during LET administration. Decreased responsiveness of Inh B was observed despite corresponding increases of FSH, which is known to enhance Inh B release. 


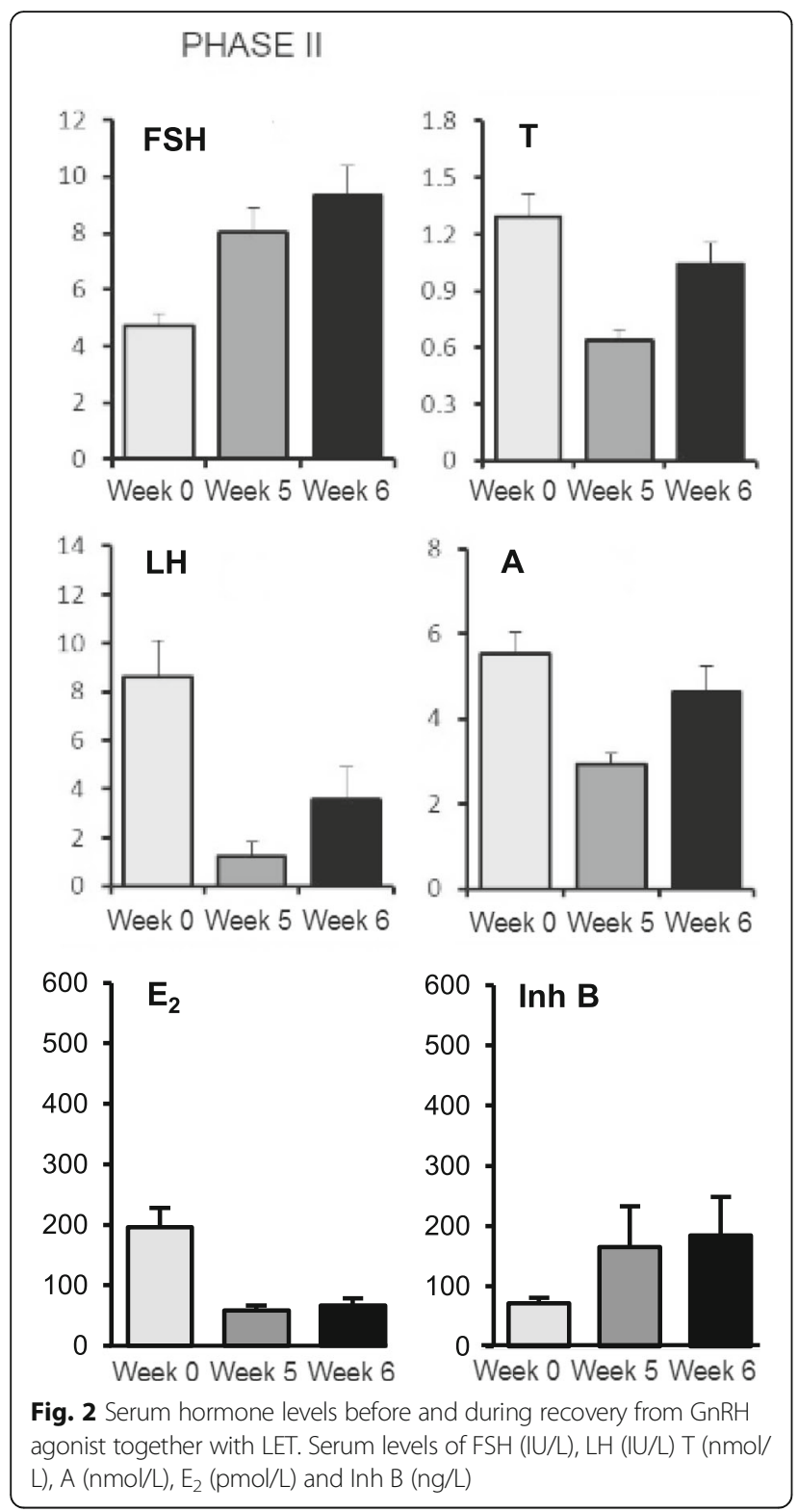

Table 2 Serum estradiol and Inh B fold-change responses to FSH at week 0 (baseline), week 5 and week 6 during Phase I (without LET) and Phase II (with LET) of study

\begin{tabular}{cccc}
\hline & Week 0 & Week 5 & Week 6 \\
\hline Estradiol & & \\
Phase I & $2.53 \pm 0.25$ & $2.14 \pm 0.24$ & $2.70 \pm 0.27$ \\
Phase II & $2.20 \pm 0.18$ & $1.39 \pm 0.16^{\mathrm{a}}$ & $1.63 \pm 0.20^{\mathrm{b}}$ \\
Inh B & & \\
Phase I & $5.31 \pm 0.55$ & $5.82 \pm 0.88$ & $6.08 \pm 0.78$ \\
Phase II & $5.50 \pm 0.25$ & $3.33 \pm 0.48^{\mathrm{a}}$ & $3.14 \pm 0.43^{\mathrm{b}}$ \\
$\begin{array}{c}{ }^{\mathrm{a}} p<0.04, \text { significantly different from Week 0 } \\
{ }_{\mathrm{b}} \boldsymbol{p}<0.01 \text {, significantly different from Week 0 }\end{array}$
\end{tabular}

Hyperresponsiveness to FSH administration in women with PCOS is a well-recognized phenomenon that predisposes to hyperstimulation during ovulation induction. This is likely due to the abundance of small antral follicles that exist in women with PCOS as well as an increased number of FSH receptors per granulosa cell in follicles from anovulatory women with this disorder $[14,15]$. However, there is a lack of clinical studies in women regarding the role of $\mathrm{E}_{2}$ on $\mathrm{GC}$ function and follicle development. As a result, most of our understanding of how $E_{2}$ impacts follicle health has been inferred from experiments in animal models. It is apparent that $E_{2}$ does not exert a direct effect on GCs as $E_{2}$ response elements have not been identified on the CYP19 promoter in the rat model or human GCs [16]. Rather, it is likely synergism between $E_{2}$ and FSH that promotes GC function and follicle growth. For instance, studies have shown that maximal FSH stimulation of aromatase activation, antrum formation, and $\mathrm{LH}$ responsiveness in GCs requires $\mathrm{E}_{2}[4,16-20]$. These findings are underscored by studies conducted in $\beta$ estrogen receptor knock out mice that demonstrate the necessity of $\mathrm{E}_{2}$ to achieve maximum FSH action in GCs [21].

There were modest increases of basal serum Inh B during LET treatment in Phase II that were not statistically significant compared to Phase I. The subtle change of Inh B may have been induced by raised levels of circulating $\mathrm{FSH}$ as a result of lowered serum $\mathrm{E}_{2}$ levels rather than an inherent increase of GC responsiveness. Nevertheless, corresponding Inh B responses to FSH were not greater than those observed prior to $\mathrm{GnRH}$ agonist administration or Inh B responses in Phase I. Thus, the incremental fold-change was significantly less in Phase II in association with diminished $E_{2}$ levels. Considering that Inh B may serve as a GC marker, this provides indirect evidence that estrogen augments $E_{2}$ responsiveness to $\mathrm{FSH}$ in women with PCOS.

While these results suggest that $\mathrm{E}_{2}$ may contribute to enhanced GC function in women with PCOS, it is less clear as to whether chronic $\mathrm{E}_{2}$ secretion directly impacts GC hyper-responsiveness to FSH as demonstrated in vitro or in women with this disorder. In the hypogonadotropic hypogonadal female, serum $\mathrm{E}_{2}$ levels are low and initial ovarian responses to exogenous FSH are decreased compared to anovulatory women with normal $\mathrm{E}_{2}$ concentrations. Estradiol has also been used in poor ovarian responders to help increase the number of mature follicles retrieved and decrease cycle cancellations [22]. By comparison, anovulatory women with PCOS are distinctive in that efforts to induce ovulation appear to assume varying and, at times, apparent diametrical ovarian responses. In PCOS women initiation of ovulation induction has been characterized by a lack of follicle response that commonly warrants higher therapeutic 
doses or more intensive treatment modalities. It has been reported that during clomiphene citrate administration significantly smaller increments of $E_{2}$ were observed compared to those of normal women despite comparable increases of serum FSH [23] As a result, several modified treatment regimens have been proposed that markedly increase the total dose of clomiphene or utilize additional drugs, including gonadotropins, to enhance clomiphene effectiveness. Primary gonadotropin therapy in women with PCOS has also been associated with poor initial ovarian responses to ovulation induction as early $E_{2}$ responses to daily gonadotropin stimulation were considerably less compared to that found in normal women [24]. The mechanism of ovarian insensitivity in the early stages of ovulation induction has not been examined. In women with PCOS, chronic $\mathrm{E}_{2}$ secretion has been attributed to peripheral extra-glandular conversion and local intra-ovarian production may be insufficient to support early follicular responses to FSH. Alternatively, multiple factors, both intra- and extra-ovarian, may be responsible for or contribute to anovulation in women with this disorder and warrant further investigation. This would include AMH's possible role in regulation of ovarian function and morphology $[25,26]$.

Despite the reduction of $\mathrm{E}_{2}$ during LET treatment, circulating levels of $\mathrm{T}$ and A were inexplicably not altered. Whether this was the result of LET superimposed on already suppressed ovarian steroidogenesis is uncertain, although it would seem that aromatase inhibition at extra-glandular sites might result in elevated serum androgens. Previously, it was reported that $\mathrm{T}$ as well as gonadotropins were unaltered in premenopausal women administered LET, $2.5 \mathrm{mg}$, daily over 12 weeks [27]. Another consideration may be that our study subjects were comprised of only those with PCOS with an elevated BMI and the results should not be generalized to a non-obese population due to BMI's influence on insulin resistance and ovarian hormones.

The experimental design of our study was complex, but necessary in an attempt to fully assess the effect of serum $E_{2}$ reduction on $G C$ function. Our previously studies have demonstrated that GnRH agonist administration may lower, but not eliminate serum $\mathrm{E}_{2}$ levels in normal and PCOS women, particularly those with increased BMI as was the case with our study subjects [12]. To maintain reduced levels of $E_{2}$ following ovarian suppression LET was employed during the interval of ovarian recovery. Use of an anti-estrogen such as a selective $\mathrm{E}_{2}$ receptor modulator may have been considered, although these compounds may bind to $E_{2}$ receptors and activate signaling pathways independent of $E_{2}$. In addition, the degree to which $E_{2}$ action was reduced would be unclear and measurement of $E_{2}$ levels would be of questionable value.
Clinical studies to examine the role of estrogen on GC function in PCOS or normal women have not been performed previously. However, the interpretation of our results warrants some caution due to the following limitations. First, there were a limited number of subjects that served as their own controls. Second, non-PCOS women were not included. Third, the stimulatory dose of FSH was relatively high and GC responses may have been maximally stimulated that precluded differential Inh B production. Fourth, in light of ovarian suppression by GnRH agonist, LET administration may have been extended to allow a lengthier recovery prior to FSH stimulation. This is unlikely as our previous studies as well as the current results suggest that adequate steroidogenesis had been reestablished by the time of FSH testing. Lastly, we elected to employ Inh B as a marker of GC responsiveness to FSH as suggested by Dokras, et. al [11]. This assumption was based on the parallelism of Inh $\mathrm{B}$ and $\mathrm{E}_{2}$ responses to variable doses of iv $\mathrm{FSH}$ in both normal and PCOS women as previously reported [12].

\section{Conclusions}

In summary, the results of this study have demonstrated that in women with PCOS Inh B responses to FSH are reduced in the presence of lowered circulating $\mathrm{E}_{2}$ levels. These finding provide indirect evidence that $E_{2}$ may enhance follicle function in women with this disorder.

\section{Abbreviations \\ 17-OHP: 17-hydroxyprogesterone; A: Androstenedione; CTRI: Clinical and translational research institute; CV: Coefficients of variation; DHEAS: Dehydroepiandrosterone sulfate; $E_{2}$ : Estradiol; GCs: Granulosa cells; Inhibin B: Inh B; LET: Letrozole; PCOS: Polycystic ovary syndrome; r-hFSH: Recombinant human FSH; RIA: Radio-immunoassay; T: Testosterone}

\section{Acknowledgements}

We are grateful to Mr. Jeff Wong for his technical expertise and to the nurses and staff of the University of California, San Diego, General Clinical Research Center for their dedicated care.

\section{Funding}

Eunice Kennedy Shriver NICHD/NIH through cooperative agreement (U54 HD12303-28) as part of the Specialized Cooperative Centers Program in Reproduction and Infertility Research, NIH T32 HD007203, and in part by NIH grant MO1 RR00827.

\section{Availability of data and materials}

The datasets used and/or analyzed during the current study available from the corresponding author on reasonable request.

\section{Authors' contributions}

MVH, MD: Analysis, Manuscript Drafting, Critical Discussion; MAR, MD: Study Design, Execution; RFS, MD: Execution; RJC, MD: Study Design, Analysis, Manuscript Drafting, Critical Discussion. All authors read and approved the final manuscript.

\section{Competing interests}

The authors declare that they have no competing interests.

Consent for publication

Not applicable. 


\section{Ethics approval and consent to participate}

The study was approved by the Human Research Protection Program at the University of California, San Diego (UCSD, IRB\#100023) and written informed consent was obtained from each participant before study.

\section{Author details}

'Reproductive Medicine, University of California, 200 West Arbor Drive MC: 8710, San Diego, CA 92103, USA. ${ }^{2}$ Reproductive Endocrinology and Infertility, Southern California Permanente Medical Group, 6650 Alton Parkway, Irvine, CA 92618, USA. ${ }^{3}$ Obstetrics and Gynecology, Southern California Permanente Medical Group, 250 Travelodge Drive, El Cajon, CA 92020, USA. ${ }^{4} 9500$ Gilman Drive \#0633 La Jolla, San Diego, CA 92093, USA.

Received: 19 January 2017 Accepted: 8 February 2017

Published online: 10 February 2017

\section{Reference}

1. Coffler MS, Patel K, Dahan MH, Malcom PJ, Kawashima T, Deutsch R, et al. Evidence for abnormal granulosa cell responsiveness to follicle-stimulating hormone in women with polycystic ovary syndrome. J Clin Endocrinol Metab. 2003:88:1742-7.

2. Erickson GF, Magoffin DA, Cragun JR, Chang RJ. The effects of insulin and insulin-like growth factors-I and -II on estradiol production by granulosa cells of polycystic ovaries. J Clin Endocrinol Metab. 1990;70:894-902.

3. Willis D, Mason H, Gilling-Smith C, Franks S. Modulation by insulin of folliclestimulating hormone and luteinizing hormone actions in human granulosa cells of normal and polycystic ovaries. J Clin Endocrinol Metab. 1996;81:302-9.

4. Adashi EY, Hsueh AJ. Estrogens augment the stimulation of ovarian aromatase activity by follicle-stimulating hormone in cultured rat granulosa cells. J Biol Chem. 1982;257:6077-83.

5. Burghardt RC, Anderson E. Hormonal modulation of gap junctions in rat ovarian follicles. Cell Tissue Res. 1981;214:181-93.

6. Jonassen JA, Bose K, Richards JS. Enhancement and desensitization of hormone-responsive adenylate cyclase in granulosa cells of preantral and antral ovarian follicles: effects of estradiol and follicle-stimulating hormone. Endocrinology. 1982;111:74-9.

7. Merk FB, Botticelli CR, Albright JT. An intercellular response to estrogen by granulosa cells in the rat ovary; an electron microscope study. Endocrinology. 1972:90:992-1007.

8. Daniel SA, Armstrong DT. Involvement of estrogens in the regulation of granulosa cell aromatase activity. Can J Physiol Pharmacol. 1983:61:507-11.

9. Richards JS, Ireland JJ, Rao MC, Bernath GA, Midgley AR, Reichert LE. Ovarian follicular development in the rat: hormone receptor regulation by estradiol, follicle stimulating hormone and luteinizing hormone. Endocrinology. 1976; 99:1562-70.

10. Richards JS, Jonassen JA, Rolfes Al, Kersey K, Reichert LE. Adenosine 3',5'monophosphate, luteinizing hormone receptor, and progesterone during granulosa cell differentiation: effects of estradiol and follicle-stimulating hormone. Endocrinology. 1979;104:765-73.

11. Dokras A, Habana A, Giraldo J, Jones E. Secretion of inhibin B during ovarian stimulation is decreased in infertile women with endometriosis. Fertil Steril. 2000;74:35-40

12. Rosencrantz MA, Wachs DS, Coffler MS, Malcom PJ, Donohue M, Chang RJ. Comparison of inhibin B and estradiol responses to intravenous FSH in women with polycystic ovary syndrome and normal women. Hum Reprod Oxf Engl. 2010;25:198-203.

13. de Ziegler D, Steingold K, Cedars M, Lu JK, Meldrum DR, Judd HL, et al. Recovery of hormone secretion after chronic gonadotropin-releasing hormone agonist administration in women with polycystic ovarian disease. J Clin Endocrinol Metab. 1989;68:1111-7.

14. Maciel GA, Baracat EC, Benda JA, Markham SM, Hensinger K, Chang RJ, et al. Stockpiling of transitional and classic primary follicles in ovaries of women with polycystic ovary syndrome. J Clin Endocrinol Metab. 2004; 89:5321-7.

15. Almahbobi G, Anderiesz C, Hutchinson P, McFarlane JR, Wood C, Trounson $\mathrm{AO}$. Functional integrity of granulosa cells from polycystic ovaries. Clin Endocrinol (Oxf). 1996:44:571-80.

16. Fitzpatrick SL, Richards JS. Regulation of cytochrome P450 aromatase messenger ribonucleic acid and activity by steroids and gonadotropins in rat granulosa cells. Endocrinology. 1991;129:1452-62.
17. Goldenberg RL, Vaitukaitis JL, Ross GT. Estrogen and follicle stimulation hormone interactions on follicle growth in rats. Endocrinology. 1972;90:1492-8.

18. Knecht M, Darbon JM, Ranta T, Baukal AJ, Catt KJ. Estrogens enhance the adenosine 3',5'-monophosphate-mediated induction of follicle-stimulating hormone and luteinizing hormone receptors in rat granulosa cells. Endocrinology. 1984;115:41-9.

19. Knecht M, Tsai-Morris CH, Catt KJ. Estrogen dependence of luteinizing hormone receptor expression in cultured rat granulosa cells. Inhibition of granulosa cell development by the antiestrogens tamoxifen and keoxifene. Endocrinology. 1985;116:1771-7.

20. Zhuang LZ, Adashi EY, Hsuch AJ. Direct enhancement of gonadotropinstimulated ovarian estrogen biosynthesis by estrogen and clomiphene citrate. Endocrinology. 1982;110:2219-21.

21. Couse JF, Yates MM, Deroo BJ, Korach KS. Estrogen receptor-beta is critical to granulosa cell differentiation and the ovulatory response to gonadotropins. Endocrinology. 2005;146:3247-62.

22. Chang X, Wu J. Effects of luteal estradiol pre-treatment on the outcome of IVF in poor ovarian responders. Gynecol. Endocrinol. Off. J. Int. Soc. Gynecol. Endocrinol. 2013;29:196-200.

23. Rebar R, Judd HL, Yen SS, Rakoff J, Vandenberg G, Naftolin F. Characterization of the inappropriate gonadotropin secretion in polycystic ovary syndrome. J Clin Invest. 1976:57:1320-9.

24. DeFazio J, Meldrum DR, Lu JK, Vale WW, Rivier JE, Judd HL, et al. Acute ovarian responses to a long-acting agonist of gonadotropin-releasing hormone in ovulatory women and women with polycystic ovarian disease. Fertil Steril. 1985:44:453-9.

25. Durlinger AL, Visser JA, Themmen AP. Regulation of ovarian function: the role of anti-Mullerian hormone. Reproduction. 2002;124:601-9.

26. Hayes E, Kushnir V, Ma X, Biswas A, Prizant H, Gleicher N, et al. Intra-cellular mechanism of anti-Müllerian hormone $(\mathrm{AMH})$ in regulation of follicular development. Mol Cell Endocrinol. 2016:433:56-65.

27. Parsanezhad ME, Azmoon M, Alborzi S, Rajaeefard A, Zarei A, Kazerooni T, et al. A randomized, controlled clinical trial comparing the effects of aromatase inhibitor (letrozole) and gonadotropin-releasing hormone agonist (triptorelin) on uterine leiomyoma volume and hormonal status. Fertil Steril. 2010;93:192-8.

\section{Submit your next manuscript to BioMed Central and we will help you at every step:}

- We accept pre-submission inquiries

- Our selector tool helps you to find the most relevant journal

- We provide round the clock customer support

- Convenient online submission

- Thorough peer review

- Inclusion in PubMed and all major indexing services

- Maximum visibility for your research

Submit your manuscript at www.biomedcentral.com/submit
) Biomed Central 